\title{
Relevância científica e educacional da Coleção de Macrofósseis da Universidade Federal do Rio de Janeiro
}

\author{
Scientific and educational relevance of the Macrofossil Collection of Rio de Janeiro Federal University
}

\author{
Flávia Alessandra da Silva Figueiredo ${ }^{1}$, Penélope Saliveros Bosio ${ }^{1}$, Rone Pacheco Ribelro ${ }^{2}$, Ismar de Souza Carvalho ${ }^{3}$ \\ 1 - Musé́loga, Instituto de Geociências, Universidade Federal do Rio de Janeiro. CCMN. Rio de Janeiro, RJ, Brasil. \\ 2 - Auxiliar em Administração, Atividades Culturais de Divulgação Científica, Instituto de Geociências, Universidade Federal do Rio de Janeiro. \\ 3 - Professor Titular, Curador Coleção de Macrofósseis e Diretor Casa da Ciência, Instituto de Geociências, Universidade Federal do Rio de Janeiro. \\ E-MAIL: FLAVIA@GEOLOGIA.ufrJ.BR,.PENELOPEBOSI0@IGE0.ufRJ.BR, RONE.RIBEIR0@IGE0.ufrJ.BR, ISMAR@GGELLGIA.ufrJ.BR
}

Abstract: This study analyses the history and curatorial practices of Macrofossil Collection of the Geology Department of Rio de Janeiro Federal University. This collection houses approximately 35,000 specimens of fossils that results from the scientific researches on the institution. This collection is used to comparative analysis of distinct geographic and time intervals allowing the research on sedimentary basin analysis and the prospection of minerals with economic importance. This is one of the most important Brazilian scientific collections that allow the training and scientific qualification of new geoscientists in the research of biostratigraphy, paleoecology and palaeoenvironmental analysis. The fossils, as a national heritage, demand curatorial care which are analyzed and evaluated in the context of a museum scientific collection in the university environment. The relevance of a paleontological collection as a register of the Earth's memory demands curatorial procedures to the preservation of this ex-situ geological heritage.

Resumo: Este estudo analisa 0 histórico de formação e as práticas de gestão para a salvaguarda da Coleção de Macrofósseis do Departamento de Geologia da Universidade Federal do Rio de Janeiro. Trata-se de um acervo de aproximadamente 35.000 exemplares de fósseis, resultado das pesquisas da instituição. A coleção possibilita a análise comparativa de distintos intervalos temporais e de áreas geográficas, possibilitando a análise de bacias sedimentares e prospecção de recursos de interesse econômico. É uma das mais importantes coleções científicas do Brasil, destinada à qualificação de profissionais para atividades de pesquisa em bioestratigrafia, paleoecologia e análise paleoambiental. Os fósseis, considerados patrimônio da União, são analisados no contexto de uma coleção científica musealizada integrante de uma instituição universitária. A relevância das coleções paleontológicas como 0 registro da memória da Terra demanda procedimentos curadoriais específicos para a preservação deste patrimônio geológico ex-situ.

\section{Introdução}

Analisar coleções e museus é uma tarefa complexa e múltipla, pois envolve a investigação de conceitos básicos e diretamente relacionados entre si, como patrimônio, memória e identidade, por meio da interpretação e divulgação de seus discursos. É compreender que essa dinâmica é ilimitada e heterogênea, de acordo com as especificidades de quem emite e de quem recebe a informação.

Consideramos como intrínsecos e indissociáveis entre si os discursos envolvendo museus, coleções, universidades e patrimônios, bem como as áreas do conhecimento correlatas ao meio em que estão inseridos. Permitem análise profunda da relação por meio da fala específica dos atores (os cientistas) e da recepção dos públicos (as comunidades). Conforme
Citation/Citação: Figueiredo, F. A. S., Bosio, P. S., Ribeiro, R. P., \& Carvalho, I. S. (2021). Relevância Científica e Educacional da Coleção de Macrofósseis da Universidade Federal do Rio de Janeiro. Terræ Didatica, 17(Publ. Contínua), 1-12, e021035. doi: 10.20396/ td.v17i00.8665780.

Keywords: Museology, Paleontology, Fossil, Curatorial Procedures, Geological Heritage.

Palavras-chave: Museologia, Paleontologia, Curadoria, Fóssil, Patrimônio Geológico.

\section{Manuscript/Manuscrito:}

Received/Recebido: 27/05/2021

Revised/Corrigido: 25/08/2021

Accepted/Aceito: 03/10/2021

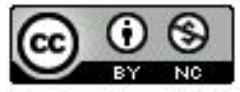

analisa Gonçalves (2007), não basta apenas afirmar que museus representam identidades, sejam elas étnicas, religiosas e/ou culturais; tais representações, feitas por meio de objetos materiais, continuam a exercer a magia e despertar o fascínio nas pessoas. Chagas (2003) destaca a importância de que tanto o remetente quanto o destinatário reconheçam e agreguem valores ao conjunto de bens, que podem ser transmitidos de uma geração para outra (perspectiva diacrônica), ou ser partilhados em uma mesma geração (perspectiva sincrônica).

Seja por motivos particulares e/ou coletivos, para recordar determinado acontecimento, lugar e/ ou uma pessoa específica, como analisa Figueiredo (2014), todos possuímos interesses diversos na acumulação de objetos, revelando, assim, nossos laços 
emocionais e racionais com a história, evidenciados por critérios de seleção, organização e exposição dos mais valiosos bens, frutos diretos da produção e evolução humana.

Para Lemos (1981), a preservação dos bens culturais é analisada como a forma mais eloquente e autêntica de transmissão das maneiras de pensar, agir e sentir das antigas às atuais gerações. Qualquer objeto ou artefato, conforme analisa Pomian (1984), pode figurar em uma coleção particular ou em um museu. Passando pelas mais variadas coleções, desde as mais populares, as mais eruditas, tal prática vai além do status econômico e ou social. Os objetos ao entrarem nesse novo mundo, perdem seu valor de uso e é, justamente, por meio da perda, que há uma consagração, elevando-os a status de objetos de coleção.

O objeto, dentro do contexto museológico, como pondera Figueiredo (2014), ao entrar no espaço de uma coleção/museu e passar por metodologias específicas de preservação, torna-se parte de um processo inevitável de perdas e ressignificações, tornando-se o centro de novas relações, pelo processo de musealização.

Conforme analisam Lima e Carvalho (2020), coleções geológicas e paleontológicas de universidades brasileiras possuem, no geral, uma metodologia muito semelhante de gestão de acervos. Entretanto, não há padronização das atividades curadoriais, prevalecendo políticas individualizadas, nem sempre documentadas, guiadas, muitas vezes, apenas pela experiência prática dos curadores e ou responsáveis.

O presente estudo analisa as particularidades envolvendo o histórico de formação e as práticas de preservação e gestão da Coleção de Macrofósseis pertencente ao Departamento de Geologia do Instituto de Geociências da UFRJ. A especificidade de seu acervo, os fósseis, considerados como patrimônio da União, são analisados dentro de um contexto particular do processo de musealização.

\section{Coleção de Macrofósseis}

O Departamento de Geologia da UFRJ possui importantes coleções que estão intrinsecamente ligadas à formação de um acervo histórico e científico que teve origem

Tabela 1. Levantamento qualitativo e quantitativo (número de registros e número de exemplares) a partir do inventário do acervo que compõe a Coleção de Macrofósseis, mostrando a grande diversidade de grupos fósseis catalogados e armazenados

\begin{tabular}{|c|c|c|c|c|}
\hline $\mathrm{N}^{\mathrm{o}}$ & Coleção & Sigla & Registros & Exemplares \\
\hline 1 & Amphibia & (A) & 11 & 43 \\
\hline 2 & Arachnida & (Ac) & 125 & 172 \\
\hline 3 & Aves & $(\mathrm{Av})$ & 128 & 174 \\
\hline 4 & Bivalvia & $(\mathrm{Bi})$ & 507 & 1510 \\
\hline 5 & Brachiopoda & $(\mathrm{Bq})$ & 461 & 916 \\
\hline 6 & Briozoa & $(\mathrm{Br})$ & 7 & 10 \\
\hline 7 & Cephalopoda & (Cf) & 109 & 304 \\
\hline 8 & Cnidaria & $(\mathrm{Cn})$ & 35 & 81 \\
\hline 9 & Conchostraca & (Co) & 501 & 2.090 \\
\hline 10 & Crustacea & $(\mathrm{Cr})$ & 248 & 425 \\
\hline 11 & Echinodermata & $(\mathrm{Eq})$ & 172 & 829 \\
\hline 12 & Gastropoda & $(\mathrm{Gp})$ & 373 & 1.195 \\
\hline 13 & Graptozoa & $(\mathrm{Gr})$ & 1 & 2 \\
\hline 14 & $\begin{array}{l}\text { Icnofóssil } \\
\text { invertebrado }\end{array}$ & (Ic) & 848 & 1.949 \\
\hline 15 & $\begin{array}{l}\text { Icnofóssil } \\
\text { vertebrado }\end{array}$ & $(\mathrm{IcV})$ & 594 & 948 \\
\hline 16 & Ignácio Brito & (IB) & 1.339 & 3.835 \\
\hline 17 & Insecta & (Ins) & 1.937 & 2.223 \\
\hline 18 & Mammalia & $(\mathrm{M})$ & 1.194 & 1.800 \\
\hline 19 & Paleobotânica & $(\mathrm{Pb})$ & 2.790 & 3.904 \\
\hline 20 & Peixe & $(\mathrm{P})$ & 1.914 & 2.909 \\
\hline 21 & Peixe dente & $(\mathrm{P}(\mathrm{d}))$ & 440 & 1.319 \\
\hline 22 & Peixe escama & $(\mathrm{P}(\mathrm{e}))$ & 499 & 2997 \\
\hline 23 & Polychaeta & $(\mathrm{Po})$ & 13 & 38 \\
\hline 24 & Reptilia & $(\mathrm{R})$ & 703 & 2769 \\
\hline 25 & Reptil dente & $(\mathrm{R}(\mathrm{d}))$ & 628 & 695 \\
\hline 26 & Scaphopoda & $(\mathrm{Sf})$ & 1 & 5 \\
\hline 27 & Tentaculata & $(\mathrm{Te})$ & 25 & 35 \\
\hline 28 & Trilobitomorpha & $(\mathrm{Tr})$ & 188 & 286 \\
\hline Totais: & & & 15.791 & 33.463 \\
\hline
\end{tabular}

no início do século 19, com a chegada da Família Real, em 1808, no Brasil. Com a transferência da corte portuguesa, o país herdou uma rica e importante coleção mineralógica trazida por D. João VI (Museu da Geodiversidade, 2013). Somando-se a esta coleção, o Departamento de Geologia, com a Coleção de Macrofósseis, também é responsável pela salvaguarda de importante acervo com quase trinta e quatro mil exemplares de fósseis (Tab. 1), além de rochas, documentos e objetos histórico-científicos, integrantes de outros laboratórios/coleções. 
A Coleção de Macrofósseis é visitável, universitária e de caráter museológico, subordinada às metodologias técnicas e à legislação vigente dos campos da Museologia e da Paleontologia. As finalidades da coleção, de acordo com seu Regimento Interno, são:

- Adquirir amostras científicas, por meio de coletas acadêmicas de campo, doações, empréstimos, permutas e alienações;

- Preservar o acervo de macrofósseis, possibilitando assim, a compreensão da evolução da vida no Planeta Terra;

- Elaborar estratégias de conservação preventiva, objetivando a salvaguarda do patrimônio fossilífero para a fruição de atuais e futuras gerações;

- Registrar e documentar todas as informações, intrínsecas e extrínsecas, relevantes à preservação de cada amostra fossilífera;

- Disponibilizar o acesso ao público, contribuindo para a divulgação do conhecimento e qualificação de novos profissionais para atividades de pesquisa;

- Desenvolver atividades de comunicação para a conscientização e valorização do patrimônio fossilífero;

- Apoiar a comunidade acadêmica, dentro e fora da UFRJ, no desenvolvimento de suas atividades de ensino, pesquisa e extensão e executar ações em parceria com o Museu da Geodiversidade e outras instituições.

Parte do acervo é formado por material da antiga Faculdade Nacional de Filosofia, parcialmente incorporado pela Coleção Ignácio Brito (Coleção IB). A coleção é formada pela inclusão deste acervo e também a partir das atividades de campo desenvolvidas e coordenadas pelo professor Ignácio Brito, vinculado ao Instituto de Geociências, cuja coleção é constituída, em sua grande maioria, por invertebrados fósseis, assunto de seu interesse e atuação.

Paralelamente à formação da Coleção IB, é iniciada a formação de uma coleção designada de Departamento de Geologia (Coleção DG), constituída por iniciativa de docentes e discentes vinculados ao Instituto de Geociências, interessados na preservação de uma maior variedade de fósseis e na criação de uma coleção de caráter institucional (Fig. 1). Dessa forma, com o passar do tempo, a Coleção IB deixa de se constituir em repositório de novos fósseis e abre espaço para a ampliação e consolidação da Coleção
DG. Portanto, a Coleção de Macrofósseis engloba a Coleção IB e a Coleção do Departamento de Geologia (DG), em crescimento até os dias atuais e que compreende quatro grandes grupos taxonômicos: paleobotânica, paleoinvertebrados, paleovertebrados e icnofósseis. A Coleção de Macrofósseis possui, aproximadamente, um acervo de mais de quinze mil registros de fósseis, sendo quase trinta e quatro mil exemplares, devidamente catalogados, oriundos de bacias intracratônicas e marginais do Proterozoico e Fanerozoico. Trata-se da preservação de uma das mais importantes coleções científicas do Brasil, destinada ao treinamento e qualificação de novos profissionais para atividades de pesquisa em bioestratigrafia, paleoecologia e análise paleoambiental.

Destaca-se, no acervo, um grande número de fósseis procedentes das bacias do Araripe, Bauru, São Luís, São José de Itaboraí, Paraná, Parnaíba, Resende, Sousa, Sanfranciscana, São José de Belmonte, Taubaté e Potiguar. Deste acervo fazem parte materiais de extrema importância, como os holótipos (tipo

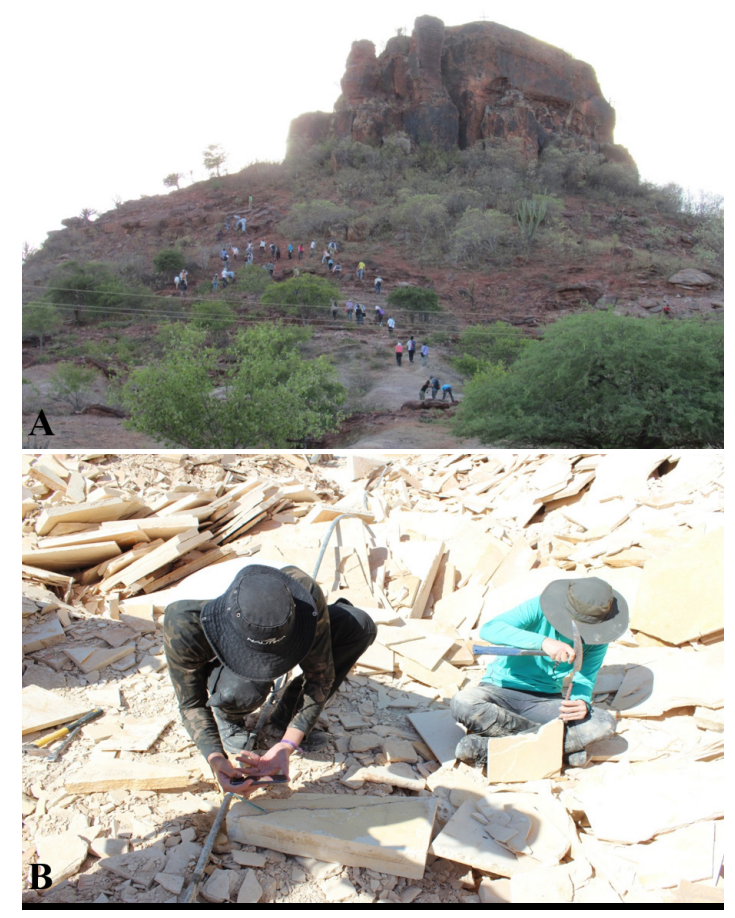

Figura 1. 0 acervo da Coleção de Macrofósseis se constituiu por meio de coleta sistemática realizada por docentes e discentes dos cursos de graduação e pós-graduação em Geociências e Biociências da Universidade Federal do Rio de Janeiro. (A). Atividade de campo na Formação Pimenteira, Bacia do Parnaíba, Estado do Piauí, em que discentes dos cursos de graduação da UFRJ são treinados na coleta de fósseis; (B). Na Formação Santana, Bacia do Araripe (Estado do Ceará), a coleta de fósseis é realizada seguindo técnicas tradicionais em lavras de calcário 
de referência científica), espécimes de referência na descrição de novas espécies e que possibilitam o resgate da história da evolução dos animais e vegetais ao longo do tempo.

\section{Museus e Coleções na Defesa do Patrimônio Fossilífero}

Durante as atividades de coleta de dados em uma área sedimentar, os fósseis são um dos elementos de maior relevância para o entendimento da evolução geológica regional. Como dados de prospecção básica, são armazenados nos acervos científicos possibilitando a análise comparativa com materiais advindos de distintos intervalos temporais e de áreas geográficas diversas, possibilitando a correlação bioestratigráfica; a aplicação na análise de bacias sedimentares; pesquisas paleoecológicas e paleoambientais e prospecção de recursos de interesse econômico.

O fóssil, enquanto patrimônio da União, necessita ser salvaguardado da melhor forma possível, para que, com isso, possa cumprir seu papel de testemunho da história e evolução da vida na Terra. Para tanto, sua preservação pode acontecer em seu local de origem (in situ) ou afastado (ex situ), ou seja, em espaços oficialmente destinados à esta prática, como, por exemplo, as Coleções e os Museus.

A conservação do patrimônio cultural é uma conjuntura de ações tomada para prevenir sua destruição e preservar ao máximo sua integridade. Contudo, os objetos e conjuntos patrimoniais podem deteriorar-se como uma consequência de sua própria vida, o que lhes garantem acumular características especiais que constituem a sua memória. Por tal motivo, a transferência de um objeto para a realidade de uma Coleção / Museu ou o estabelecimento de um contexto museológico, é uma das formas para sua conservação. Os artefatos materiais, portadores de carga simbólica e filosófica, ao entrarem para estes espaços musealizados, passam por processos de escolhas e valorações que os elevam a status de bens patrimonializados e representantes de uma memória individual e/ou coletiva (Figueiredo, 2014).

A noção de patrimônio da forma como trabalhamos atualmente, conforme analisa Abreu (2007), está diretamente relacionada a uma percepção linear de tempo, completamente dinâmica e intermediária nos debates de esquecimentos e lembranças. É importante destacar que essa noção foi pensada na conjuntura da sociedade ocidental moderna e que está diretamente ligada a uma noção de herança particular e que não fará sentido em qualquer contexto.

Ao analisarmos a proteção específica do patrimônio fossilífero no Brasil, verificamos que, somente a partir da Constituição de 1988, mais especificamente no Artigo 20, é que os fósseis começam a ser mais evidenciados como bens da União. Da Constituição (Brasil, 1988), destaca-se também a responsabilidade do Estado na defesa do patrimônio natural e a ênfase ao patrimônio paleontológico enquanto parte do patrimônio cultural brasileiro.

Neste contexto, em conformidade com a legislação local, reafirmamos a importância das coleções e dos museus na preservação do patrimônio de um país, destacando também, as suas responsabilidades diante do desenvolvimento sociocultural da comunidade em que estão inseridos. São mediadores de uma teia de ligações inseparáveis da realidade social, cultural, política, econômica em que se encontram. Portanto, falar destes espaços, é falar de responsabilidade e engajamento social.

O Estatuto de Museus (2009), importante documento de gestão do patrimônio museológico brasileiro, identifica a responsabilidade dos museus diante da salvaguarda dos patrimônios, estabelecendo assim, políticas adequadas de conservação e segurança de acervos museológicos. Determina também que o estudo e a pesquisa, além de todas as políticas envolvidas, como, por exemplo, as de aquisição e descarte, fundamentem todas as ações desenvolvidas, em todas as áreas do museu e de forma rígida.

A Coleção de Macrofósseis, portanto, estabelece suas ações em torno da legislação vigente no Brasil, obedecendo, atualmente, as diretrizes da Agência Nacional de Mineração por meio do sistema COPAL (sistema de controle da pesquisa paleontológica).

\section{Coleções paleontológicas/universitárias, educação e responsabilidade institucional}

Coleções paleontológicas nos permitem testemunhar mais de perto a história de evolução do Planeta Terra, pelo conhecimento de sua biodiversidade e geodiversidade ao longo do tempo, contribuindo assim, para o desenvolvimento e aperfeiçoamento de pesquisas e atitudes ligadas 
à valorização da ocupação do homem no Planeta, sejam elas econômicas, tecnológicas, climáticas, geográficas, sociais, históricas, biológicas e ou geológicas.

O acervo paleontológico em sua amplitude (litologia, período, tafonomia, localização) é o registro físico da diversidade paleobiológica do planeta (Cruz, 2019). Graças a esse acervo compreendemos a diversidade dos acontecimentos e fenômenos que acarretaram as transformações ambientais (físico-químicas) durante a história geológica do Planeta Terra.

Brilha (2005) nos lembra que a geodiversidade apresenta valores científicos e educativos inegáveis. A investigação científica pode ser no âmbito fundamental e aplicado, em que a primeira ajuda-nos a conhecer e interpretá-la e a reconstituir a história da Terra e a segunda contribui para melhorar a relação da espécie humana com o seu meio. Já o valor educativo só pode ter sucesso se permitir o contato direto com a geodiversidade, por meio de atividades educativas formais ou não formais. A Coleção de Macrofósseis, ligada à gestão universitária, orienta as ações de preservação e educação para garantir a continuidade dessa história. Sua missão é mediar os processos de transformação das relações ocorridas no tempo entre espaços de memória (coleções/museus), o avanço científico/ tecnológico e as formas de pensar e agir.

É extremamente difícil delimitar e traçar o perfil das coleções e museus universitários brasileiros, pois existe uma grande variedade de formas e conteúdos, além de uma estrutura organizacional muito diferenciada de uma instituição para outra. Porém, apesar das grandes diferenças, laços se fortalecem por meio de ações comuns, como o ensino, a pesquisa e a extensão. Justamente nesse sentido, as possibilidades de propostas conjuntas se constituem. Porém, ao lembrarmos da discussão central, ou seja, a mediação entre salvaguarda e comunicação dos testemunhos patrimoniais, destacamos a importância da utilização dos processos museais, muitas vezes esquecidos, no cumprimento adequado dos objetivos.

Conforme analisa Semedo (2005), tanto o museu quanto a universidade são instituições centrais de discussão pública, que têm levado a importantes reflexões sobre objetivos, papéis e responsabilidades, tornando-os agora parceiros diante o desenvolvimento sociocultural da comunidade em que se inserem. A relação não deixa de ser conflituosa, contudo, já que a maior parte das ativida- des universitárias permanece compartimentada no âmbito disciplinar restrito, o que se reflete também na postura dos museus/coleções, criando-se um verdadeiro contrassenso em relação às definições de Museus e Museologia, que é vista normalmente como uma área interdisciplinar por natureza e que mobiliza muitos saberes na sua função de reconstrução. Ainda segundo Semedo, outro aspecto se torna relevante na relação: a necessidade de acesso a objetos e coleções no ensino e na pesquisa universitária. Tal necessidade já seria suficiente para justificar a formação e preservação de coleções e museus universitários (Figueiredo, 2014), porém se de um lado essa é uma de suas funções básicas, por outro, é o cerne principal de discussão entre as áreas do conhecimento responsáveis pela gestão, já que envolvem maneiras diferentes de pensar e agir de alguns questionamentos importantes como: preservação, acesso, uso, disponibilização e investigação.

Apesar das dificuldades dessa relação e com os esforços de ambas as partes na tentativa de maior proximidade e cooperação, a Universidade Federal do Rio de Janeiro, por meio da Coleção de Macrofósseis, torna-se responsável pela preservação e divulgação desse importante patrimônio, reconhecidamente de interesse de todos e não restrito apenas à demanda interna acadêmica, conforme legislação vigente de defesa do patrimônio nacional e gestão de museus e coleções musealizadas. Exerce também função de educação, segundo os pilares da gestão universitária, de ensino, pesquisa e extensão. A Coleção de Macrofósseis está inserida neste contexto, e assim norteia os debates e campos de atuação. Seu objetivo é intermediar conceitos como museologia e paleontologia, coleções e universidades, coleções científicas e preservação, preservação e divulgação científica e patrimônio e memória, tendo como base as áreas da Paleontologia, Geologia, Biologia, Geografia, Museologia, entre outras, dentro de um espaço múltiplo e desafiador.

\section{Curadoria e Gestão da Coleção de Macrofósseis}

A Coleção de Macrofósseis está subordinada aos procedimentos técnicos e à legislação vigente dos campos da Museologia e da Paleontologia. A Coleção é formada por uma equipe interdisciplinar, coordenada por museólogos, tendo como curador um professor/pesquisador da área da Paleontologia,

\begin{tabular}{c|c|c|c|c|c}
\hline (C) Terrae Didat. & Campinas, SP & v.17 & $1-12$ & e 021035 & 2021 \\
\hline
\end{tabular}


que desenvolve uma política de gestão de acervos baseada em um trabalho de administração técnica e pessoal, voltada a acervos científicos musealizados. Trata-se de uma política registrada e direcionada aos parâmetros de salvaguarda do patrimônio fossilífero que envolvem ações de conservação, documentação, seleção/aquisição, descarte/doação, pesquisa, comunicação/disseminação e preparação do acervo. Uma gestão que leva em consideração a missão e os objetivos da instituição, a necessidade de investigação do acervo e os caminhos para a sua preservação.

\section{Conservação}

A equipe técnica da Coleção de Macrofósseis procura guiar as estratégias conservativas em torno de ações preventivas, que evitem e/ou retardem, ao máximo, danos e intervenções que coloquem em risco a salvaguarda do patrimônio. Para tanto, trabalha com o conceito de conservação preventiva, que é definido como um conjunto de ações destinadas a minimizar processos de deterioração e/ou perdas de memória. Envolve a concepção, coordenação e execução de um conjunto de estratégias sistemáticas e organizadas, desenvolvidas por uma equipe interdisciplinar, a fim de preservar e difundir os testemunhos patrimoniais.

Para tanto, as propostas direcionadas à preservação da Coleção de Macrofósseis baseiam-se, principalmente, nas metodologias da conservação preventiva que envolvem a adequação dos suportes de acondicionamento; avaliação do estado de preservação do acervo e identificação de necessidades pontuais de conservação e restauração.

Desde o momento de reorganização do acervo e como parte de uma rotina de preservação, outras medidas de conservação preventiva são adotadas, como o controle de: acesso e saída do acervo; fatores ambientais (climáticos, biológicos e mecânicos); manuseio; transporte e segurança (Fig. 2).

Coleções constituídas por fósseis, assim como outros acervos museológicos, também necessitam de ações específicas e de um planejamento adequado à sua perfeita conservação. Dependendo da composição da rocha e do tipo de organismo ali preservado, somados aos fatores externos de deterioração, como o seu local de guarda ou de exposição, ou das técnicas empregadas de acondicionamento, manuseio ou transporte, o fóssil, pode se tornar também um material muito vulnerável.

Conforme analisa Cruz (2019), os tipos lito- lógicos, os quais os fósseis estavam inseridos, e o tempo de exposição aos fatores climáticos, são determinantes para a manutenção da integridade dos acervos. Após retirados de seu contexto original, os fósseis sofrem ações de agentes físicos e químicos ambientais, diferentes dos que agiam sobre os afloramentos em que foram extraídos e que comprometem a sua durabilidade, como luminosidade, umidade, temperatura e poluição.

A partir da incorporação do fóssil a uma coleção, a sua deterioração tem quase sempre uma direta relação com a natureza da matriz rochosa em que está inserido, ou com sua composição mineralógica. Climas quentes e úmidos são extremamente agressivos, pois aceleram as reações químicas e facilitam a colonização de superfícies expostas por fungos. Desta forma, materiais carbonáticos são muito susceptíveis à agressão por soluções ácidas. Poeira e poluentes são geralmente os grandes responsáveis por fenômenos corrosivos, daí a importância

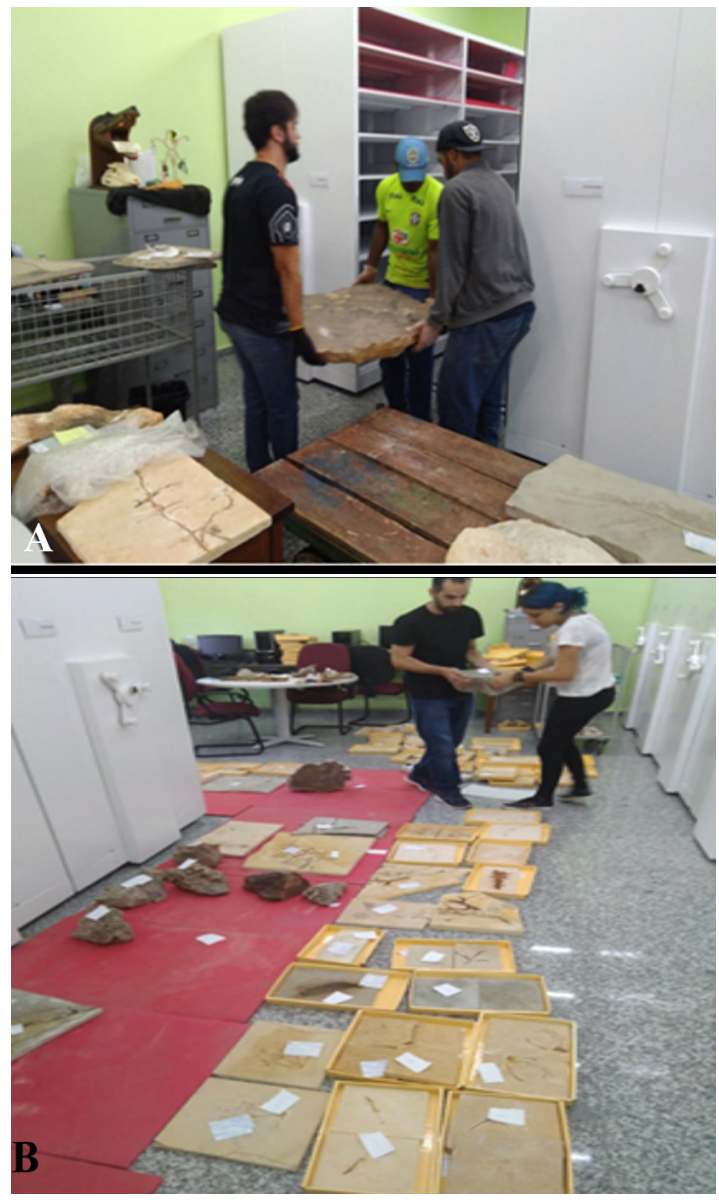

Figura 2. Manejo do acervo da Coleção de Macrofósseis da Universidade Federal do Rio de Janeiro. (A). Formas de manejo dos espécimes tombados na coleção; (B). Reorganização física do acervo, com agrupamento por níveis taxonômicos 
de se controlar e ou impedir totalmente a entrada dos agentes. A combinação entre elementos orgânicos, tais como os palinomorfos, e alta taxa de umidade, está sujeita a servir de substrato nutritivo para bactérias e fungos. Já em condições muito secas, o processo de desidratação em rochas ricas em matéria orgânica, como os folhelhos, conduz ao ressecamento, à fissura, e ao descamamento (Carvalho, 2010).

Uma estratégia adotada na conservação de material fossilífero é a replicação de originais, visando a sua preservação e o uso em atividades acadêmicas e de difusão científica. São cópias fiéis feitas a partir dos originais pertencentes à coleção científica. Apesar de ser considerada uma ação eficaz, torna-se inviável diante da diversidade dos acervos e das dificuldades operacionais de confecção. mento) são suportes de informação, conforme pondera Cândido (2006), o principal desafio de uma instituição museológica é preservar o objeto e a possibilidade de informação que ele contém e que o qualifica como documento. Objetos só se tornam documentos quando são interrogados de diversas formas, sendo suportes de informações intrínsecas e extrínsecas que necessitam ser investigadas. Como parte integrante dos mecanismos de preservação do Patrimônio Cultural, os museus têm o papel de criar métodos especiais que permitam o levantamento e o acesso à essas informações das quais os objetos museológicos são suportes, estabelecendo a mediação entre o indivíduo e o acervo preservado.

O objeto de coleção / museu, além de ser carregado de significados e informações, também é

De modo geral, o processo de conservação de fósseis é bem complexo e amplo, pois demanda uma análise individual de todos os tipos de suportes encontrados (rochas) e de todos os tipos de materiais fossilíferos ali preservados. Assim como em outras áreas, exige conhecimento interdisciplinar e um conjunto de estratégias bem definido. Algumas situações específicas de conservação tornam-se verdadeiros desafios à curadoria dessas coleções (Fig. 3).

\section{Documentação}

É a partir da contribuição, principalmente, da área da Ciência da Informação, que pautamos nossas ações de documentação, visando a gestão de eficientes sistemas de entrada, acesso e disseminação da informação.

Se objetos museológicos (objetos-testemunho / objetos-docu-

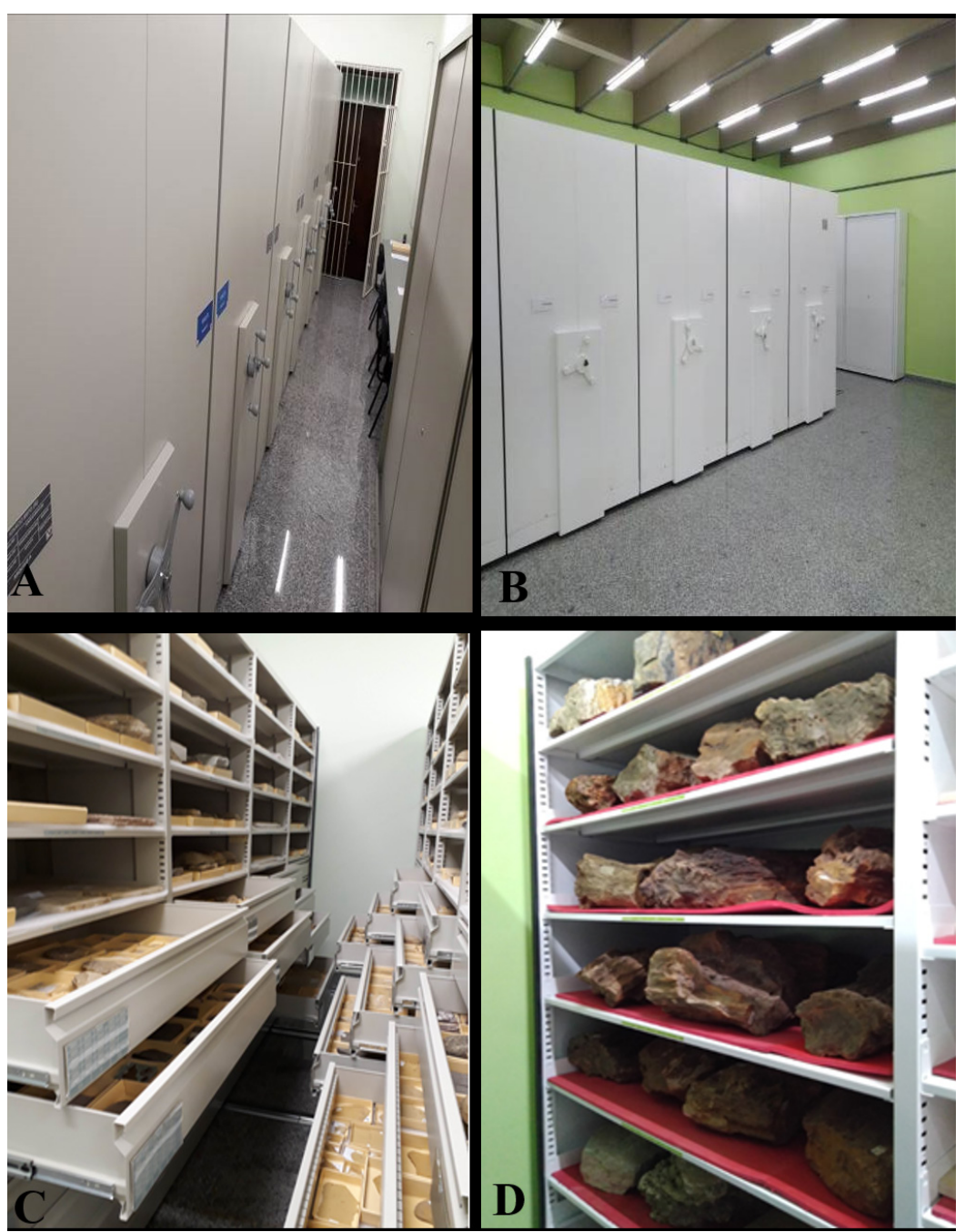

Figura 3. Novo espaço do acervo Coleção de Macrofósseis da Universidade Federal do Rio de Janeiro, revitalizado com base nos conceitos de conservação preventiva: novas salas para reserva técnica $(A, B)$, e acondicionamento adequado em compactadores de aço, com gavetas (C) e prateleiras (D) 
fonte de valor simbólico e veículo informacional. Características estas que o evidenciam enquanto representante autorizado de um determinado fato/ situação ocorrido no tempo e no espaço.

Para obtermos um eficiente sistema de Documentação Museológica, precisamos ter controle e cuidado com: entrada e saída de objetos, registro, catalogação, indexação, classificação, entre outros. A entrada de dados, além de clara, precisa e normalizada, deve ter sua terminologia controlada (Ferrez, 1994).

Um sistema eficiente de documentação possibilita a gestão adequada de coleções museológicas, evitando também problemas ligados a perdas por falta de organização e controle, roubos e extravios, na medida em que faz com que o museu divulgue ao mundo, o domínio de suas propriedades. De acordo com Kunzler et al. (2014) o processo de musealização adotado para fósseis, rochas e minerais também pode ser utilizado para a conservação de suas reproduções e informações relacionadas. A documentação, parte do processo de preservação, por exemplo, de cartas, mapas, cadernetas, publicações científicas raras e / ou históricas e/ou dados científicos não publicados, possibilitam a recuperação de dados essenciais, como sítios que já foram destruídos pelo crescimento das cidades ou exploração comercial.

A Coleção de Macrofósseis, possui como sistema de documentação, o preenchimento de uma ficha catalográfica, contendo informações básicas, referentes aos dados de coleta, de cada exemplar, com as seguintes informações: Número de Registro, Número de Exemplares, Nome, Bacia, Unidade, Procedência, Idade, Data, Coletor e Observações. Essa ficha, disponibilizada em um fichário manual, é duplicada em fichas individuais, denominadas fichas de guarda, que são dispostas junto à cada objeto.

A proposta para readequação do sistema de documentação e informação da Coleção de Macrofósseis, parte, primeiramente, de uma normatização técnica com a padronização de seus vocabulários, havendo assim, um controle na entrada de dados e uma eficaz e rápida recuperação da informação. O plano de documentação envolve também o inventário completo das coleções; o mapeamento e organização informacional do acervo nas reservas; migração para o meio digital das fichas de guarda (substituição do suporte papel danificado pelo tempo e pelo ataque de pragas, e pesquisa, complementação e correção das informações); elaboração de base de dados específica para a documentação de coleções científicas (em andamento), conten- do novos campos informacionais, destacando-se a presença da pesquisa museológica; criação (em planejamento) de um terminal de consulta online e offline, eliminando o manuseio desnecessário e resguardando a instituição como repositória legal de proteção deste bem, contribuindo assim, também nas estratégias de conservação preventiva do acervo e criação de gráficos estatísticos para o controle de entrada e saída de dados.

\section{Políticas de seleção, aquisição, descarte e doação}

As políticas de seleção, aquisição, descarte e doação, adotadas pela Coleção de Macrofósseis, são pertinentes aos objetivos da instituição e estão em acordo com a legislação interna (Regimento Interno) vigente. Desta forma, garantem uma padronização de suas ações e respaldo técnico à instituição.

Tais políticas, estão condicionadas à decisão do Curador. Em caso de dúvidas ou questionamentos, apontados por um dos Núcleos pertencentes à estrutura organizacional da Coleção, poderá ser formada uma Comissão de Aquisição e Descarte de Acervo, constituída por docentes e/ou pesquisadores convidados à critério do Núcleo de Museologia e/ou do Curador.

Os fósseis que não forem incorporados à coleção científica serão: descartados, por deterioração ou falta de interesse científico; destinados à coleção didática pertencente ao Departamento de Geologia ou encaminhados para posse, por período indeterminado, a outras instituições de ensino e/ou pesquisa. A decisão sobre o destino das amostras que não se enquadrem na coleção científica seguirá a mesma recomendação acima.

\section{Pesquisa}

Dentro de espaços musealizados, a pesquisa deve ser encarada como um dos principais agentes para a preservação e divulgação da memória. É por meio dela que os processamentos técnicos ganham sentido e atingem seus reais objetivos. A pesquisa é a principal ferramenta, por exemplo, de um eficaz sistema de documentação.

A pesquisa realizada pela Coleção de Macrofósseis, procura ser encaminhada de forma interdisciplinar, flexível e adaptável às necessidades momentâneas, procurando englobar todos os projetos em execução e em conformidades com as políticas de preservação.

\begin{tabular}{c|c|c|c|c|c}
\hline (C) Terrae Didat. & Campinas, SP & v.17 & $1-12$ & $\mathrm{e} 021035$ & 2021 \\
\hline
\end{tabular}




\section{Comunicação}

A comunicação em espaços museológicos se dá a partir do desenvolvimento de estratégias de divulgação e intercâmbio de suas atividades, que envolvem seus acervos, políticas e pesquisas com a sociedade. Trata-se do contato do homem com o objeto/ bem cultural musealizado, gerando, a partir daí, uma teia de significados e interações passíveis de múltiplas interpretações e resultados. É neste momento que, cada indivíduo, de acordo com a sua experiência pessoal/cultural, irá agregar novos conhecimentos e possibilidades de geração de novos resultados.

A Comunicação em Coleções e Museus é uma das etapas da gestão/ curadoria de acervos, e a principal em relação ao cumprimento de seus objetivos básicos de servir à comunidade em que estão inseridos. É por meio de ações, como: exposições de longa duração; exposições temporárias; exposições itinerantes; divulgação científica resultantes de suas pesquisas; plataformas gráficas e digitais de divulgação dos acervos e atividades; mostras e eventos culturais; entre outros, que acontecem os processos de comunicação (Fig. 4).

As estratégias de comunicação da Coleção de Macrofósseis vêm sendo adotadas também de modo a conscientizar a comunidade sobre a importância de preservação deste rico patrimônio, com a elaboração

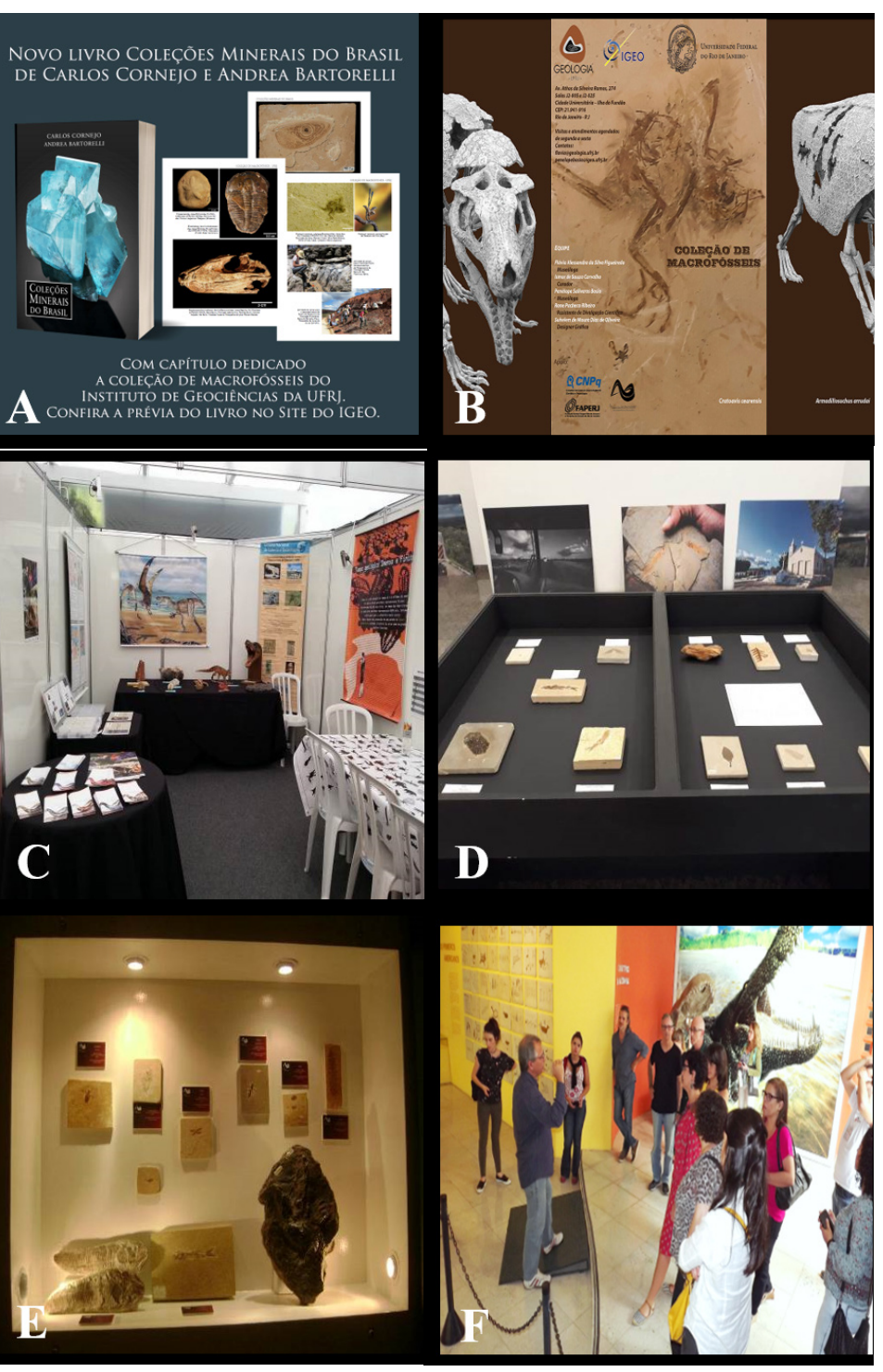

Figura 4. Meios de difusão do acervo da Coleção de Macrofósseis por divulgação impressa e exposições. (A). Catálogo "Coleções Minerais do Brasil"; (B). Folder; (C). Semana Nacional de Ciência e Tecnologia; (D). Exposição temporária; (E e F). Exposição de longa duração, Museu da Geodiversidade (UFRJ)

de: materiais didáticos, culturais e científicos; políticas direcionadas de gestão e suportes de recuperação e divulgação da informação.

A Coleção de Macrofósseis tem servido como principal veículo de divulgação de relevantes trabalhos científicos na área de Paleontologia, Museologia, Geologia, Biologia e áreas afins, atuando nas esferas de ensino, pesquisa e extensão universitária.

\section{Preparação}

Após coleta em campo e chegada à coleção, o fóssil passa por uma triagem e é separado entre coleção científica (materiais de maior relevância e representatividade), coleção didática (materiais destinados às atividades acadêmicas), doação ou descarte. Após esta etapa, uma grande parte do material, a ser incorporado, principalmente, na coleção científica, passa, muitas vezes, pelos mecanismos de preparação, um dos processos de gestão de coleções paleontológicas, que é o processo de remoção do sedimento ou rocha (matriz) que envolve os fósseis, objetivando a exposição dos detalhes anatômicos. A técnica é altamente delicada; envolve diretamente a preservação das informações que deverão ser analisadas. A preparação pode ser mecânica e/ou química. Na prepa-

\begin{tabular}{c|c}
\hline (c) Terrae Didat. & Campinas, SP \\
\hline
\end{tabular} 
ração mecânica são utilizadas algumas ferramentas específicas como canetas pneumáticas, talhadeiras e instrumentos odontológicos, onde o objetivo é ir retirando, paulatinamente, camadas de sedimentos e sujidades, de modo a revelar o material fossilífero ali preservado. Já na preparação química, utilizam-se produtos como ácido acético, ácido fórmico e peróxido de hidrogênio que promovem uma dissolução do material rochoso onde está o fóssil para a sua avaliação. Estas preparações tradicionais, mostram-se fundamentais em algumas situações, porém é amplamente reconhecido que conduzem à destruição de dados relacionados aos tecidos moles e de estruturas anatômicas delicadas, que são geralmente fundamentais para os estudos que envolvam a reconstituição em vida de plantas e animais, bem como para entendimento de aspectos de paleoecologia.

Outros procedimentos como tomografias; técnicas utilizadas em microscópio eletrônico de varredura com EDS acoplado; micro espectroscopia RAMAN, para geração de fotomicrografias e imagens digitais de alta resolução, são considerados não-invasivos. $\mathrm{O}$ advento das técnicas digitais em estudos paleobiológicos permite estudar com melhor acurácia, a tafonomia e geoquímica dos fósseis. Assim há a possibilidade de análise de feições em escalas nanométricas inclusas nas micro fábricas, permitindo uma ampla gama de interpretações acerca dos mecanismos envolvidos na preservação dos organismos, que antes não poderiam ser feitas sem o advento das técnicas digitais. Além disso, é possível identificar feições morfo-anatômicas, como tecidos e até órgãos, fossilizados, com geração de imagens de alta resolução.

\section{Discussão}

Os processos históricos relacionados à criação da Universidade Federal do Rio de Janeiro e, consequentemente, do seu Curso de Geologia que, por meio de suas diretrizes pedagógicas específicas, possibilitaram a formação de importantes coleções geológicas, consideradas patrimônios da União, demonstraram à importância da responsabilidade institucional na gestão e salvaguarda dessas coleções. Além de evidenciar sua missão educacional e inclusão nos debates de ensino, pesquisa e extensão universitária.

Ao longo do processo histórico de formação e preservação da Coleção de Macrofósseis, percebemos que a relação Coleção/Museu e Universidade ainda necessita ser amadurecida, devido, principalmente, à complexidade e heterogeneidade dos objetivos e missões dessas instituições, devendo, neste caso, haver um equilíbrio maior entre as necessidades legais do bem a que se pretende salvaguardar e os espaços destinados à esta prática e as ações de ensino, pesquisa e extensão do meio em que estão inseridos.

Coleções científicas universitárias, de caráter museológico, devem ser geridas em concomitância com as normas determinadas pelos setores museológico e de defesa do patrimônio. Caso contrário teríamos que ponderar a possibilidade de existirem diferentes definições e recomendações para coleções /museus de acordo com a tipologia encontrada. Para tanto, evidenciamos o caráter museológico da Coleção de Macrofósseis, justamente, por meio da especificidade de seu acervo, ou seja, o fóssil, patrimônio da União por natureza. De modo geral, coleções paleontológicas e arqueológicas universitárias devem ou deveriam ser geridas de acordo com a legislação de preservação dos patrimônios e dos ambientes ex-situ, ou seja, coleções e museus, em que estão inseridos.

Sabemos que os museus, ao longo da história, assumiram papel de destaque diante do processo de institucionalização das ciências no Brasil que, considerados órgãos de pesquisa, antecederam em muitos anos a criação das primeiras universidades no país. Portanto, trabalhamos com essa relação estreita entre os processos de formação e gestão de coleções paleontológicas e o mundo das coleções e dos museus. A gestão de coleções paleontológicas, de caráter museológico, deve ser direcionada, independentemente, da tipologia à que está vinculada, como um bem de interesse da sociedade como um todo e não apenas de pequenos e restritos grupos especializados.

Nesse sentido, o objeto, portador de múltiplos significados, ao entrar para o mundo das coleções e museus adquire, por meio de processos específicos, características próprias que estão, indiscutivelmente, associadas ao saber do campo museológico e, consequentemente, das propostas de salvaguarda de patrimônios culturais/científicos orientadas por meio de ações curadoriais. A Museologia, portanto, é considerada uma área do conhecimento detentora de um olhar de reflexão e de metodologias adequadas de conservação, documentação investigação e comunicação, que consegue estabelecer importantes relações entre o homem e seus testemunhos patrimoniais, ao longo da história.

Devido à sua relevância patrimonial, social, cultural e educacional nas esferas da universidade, das coleções e dos museus, a Coleção de Macrofósseis torna-se referência para pesquisas nas áreas de Pale- 
ontologia, Biologia, Geografia, Museologia e Patrimônio, entre outras. No mais, a relevância econômica das bacias sedimentares no âmbito da geologia do petróleo, demonstra que acervos científicos de fósseis são fundamentais para o treinamento e qualificação de novos geocientistas e também para a aplicação na prospecção de recursos naturais como óleo e gás. Desta forma, a Coleção é compreendida com um campo de atuação dinâmica e multidisciplinar.

Os investimentos aplicados, a gestão adequada de metodologias curadoriais e os esforços direcionados à preservação da Coleção de Macrofósseis, aumentam significativamente as condições de estudo e as possibilidades de intercâmbios informacionais e divulgação científica. Contudo, apesar dos grandes avanços realizados nos últimos anos em termos de organização e comunicação, ainda nos resta o grande desafio de como planejar adequadamente sua estrutura administrativa, de forma a relacionar campos complementares, mas altamente específicos em suas missões, como universidade; coleção científica isolada de um organismo maior, como um museu; hierarquia institucional de responsabilidade de gestão do acervo, entre outros.

Apesar das recomendações legais do campo dos museus e do patrimônio e a especificidade de seu acervo, ainda verificamos uma certa dificuldade na conciliação entre as expectativas de acesso ao acervo e as restrições necessárias para sua preservação, abrindo, desta forma, discussões sobre sua adequada gestão. Como exemplos, citamos a criação do Regimento Interno e da Política de Gerenciamentos e Usos do Acervo (Política de Acervos), documentos voltados, principalmente, à preservação dos reais objetivos $\mathrm{e}$ missões, mas que não possuem uma grande visibilidade dentro da instituição, o que gera, a médio e longo prazo, um grande risco de descaracterização e desmonte dos acervos institucionais. Desta forma, entra também, o desconhecimento sobre os reais papéis (ações, deveres e responsabilidades) dos gestores, o que torna bastante frágil todo o processo de administração. Ao trabalharmos com patrimônio, devemos sempre projetar nossas ações e objetivos pensando no futuro e, principalmente, lembrarmos da extemporaneidade dos gestores e cargos. Portanto, um dos nossos principais desafios e, talvez mais imediato, é demonstrarmos a importância da Coleção na preservação deste rico patrimônio para a sua própria comunidade (dirigentes, gestores, docentes, discentes e técnicos).

Compreendemos também que existe uma grande necessidade de evidenciar a Coleção como sendo de interesse e responsabilidade de todos, reafirmando assim, a verdadeira missão de uma instituição que lida com a gestão de patrimônios. Assim, entendemos também, a necessidade de maior interação entre os departamentos, unidades e até mesmo coleções cujos interesses e objetivos são os mesmos, consolidando assim, sua função de produtora e disseminadora de conhecimentos.

\section{Conclusões}

A análise das ações e estratégias de metodologias curadoriais permitiu evidenciar os reais desafios de gestão da Coleção de Macrofósseis da Universidade Federal do Rio de Janeiro, como: contrabalancear necessidades impostas pelas realidades universitária e patrimonial; aliar mecanismos da preservação patrimonial aos da pesquisa universitária; colocar-se entre os objetivos e a missão das coleções e museus, assim como dos dispositivos legais e as necessidades da comunidade paleontológica envolvida; mostrar à comunidade a importância do emprego adequado da técnica profissional para salvaguarda do patrimônio e sensibilizar sobre a importância das coleções / museus e dos patrimônios para o desenvolvimento da sociedade como um todo.

A gestão da Coleção de Macrofósseis, ao longo dos anos, tem se mostrado adequada no cumprimento sistemático de ações curadoriais voltadas à salvaguarda de coleções científicas musealizadas. $\mathrm{O}$ estabelecimento teórico e prático de uma política/ rotina interna orientada permitiu o estabelecimento de condições satisfatórias à guarda, pesquisa e divulgação deste importante patrimônio.

O futuro da Coleção de Macrofósseis da Universidade Federal do Rio de Janeiro é repleto de possibilidades, principalmente, diante de um mundo dinâmico e plural, em que as formas de pensar, agir e gerir estão em constantes transformações, como nas esferas educacionais, sociais, culturais, econômicas e políticas.

Os desafios futuros se dão, principalmente, por busca de teias de suportes internos e externos à instituição, que possam interligar a Coleção de Macrofósseis aos temas e problemáticas comuns a instituições afins. Nos últimos anos, com a visibilidade das coleções universitárias e, principalmente, com os destaques de suas demandas e fragilidades, é de extrema importância levarmos a discussão sobre sua salvaguarda aos órgãos federais, estaduais e/ou municipais de defesa do patrimônio e aos dirigentes superiores da universidade em que está vinculada, ampliando assim, as responsabilidades de preservação

\begin{tabular}{c|c|c|c|c|c}
\hline (C) Terrae Didat. & Campinas, SP & v.17 & $1-12$ & $\mathrm{e} 021035$ & 2021 \\
\hline
\end{tabular}


e as possibilidades de crescimento. Como exemplo, propomos aos especialistas da área, um estudo sobre a viabilidade de tornar o conjunto que compõe a Coleção de Macrofósseis da Universidade Federal do Rio de Janeiro, um bem de interesse público, junto ao Instituto Brasileiro de Museus (IBRAM), permitindo assim, um sistema de proteção mais eficaz.

A Coleção de Macrofósseis resgata e preserva o passado, administra o presente e se abre às novidades de um futuro, até então impossíveis de serem previstos e/ou planejados, mas sempre buscando melhores soluções que possam salvaguardar e comunicar da melhor forma possível estes testemunhos da história da Terra.

\section{Agradecimentos}

Os autores agradecem aos docentes, técnicos e discentes desta instituição, especialmente os do Departamento de Geologia (Instituto de Geociências) da UFRJ que, durante décadas, desenvolvem um trabalho incansável de salvaguarda do acervo. Apoios financeiros do Conselho Nacional de Desenvolvimento Científico e Tecnológico (CNPq), Fundação de Amparo à Pesquisa do Estado do Rio de Janeiro (FAPERJ) e Royal Dutch Shell (Shell) viabilizaram as ações propostas pela Coleção de Macrofósseis.

\section{Referências}

Abreu, R. M. (2007). Patrimônio Cultural: Tensões e Disputas no Contexto de uma Nova Ordem Discursiva. In: Lima Filho, M.F., Beltrao, J.F., Eckert, C. (Orgs.). Antropologia e patrimônio cultural: diálogos e Desafios contemporâneos. Associação Brasileira de Antropologia, Blumenau: Nova Letra, 263-285.

Agência Nacional de Mineração (ANM). 2021. Sistema COPAL. URL: https://app.anm.gov.br/Copal/ Login?ReturnUrl=\%2fcopal. Acesso 27.08.2021.

Brasil. (1988). Constituição da República Federativa do Brasil. Brasília, DF. URL: https://www.senado.leg.br/atividade/const/con1988/con1988_08.09.2016/art_20_. asp. Acesso 01.10.2021.

Brasil. (2009). Lei No 11.904, de 14 de janeiro de 2009. Institui o Estatuto de Museus e dá outras providências. Brasília, Presidência da República, Casa Civil. URL: https://www.planalto.gov.br/ccivil_03/_Ato20072010/2009/Lei/L11904.htm. Acesso $\overline{2} 7.0 \overline{8} .2021$.

Brilha, J. (2005). Patrimônio Geológico e Geoconservação: a conservação da natureza na sua vertente geológica. Viseu: Palimage Editores. 190p.

Cândido, M. I. (2006). Documentação Museológica. Caderno de diretrizes museológicas I. 2 ed. Brasília: Ministério da Cultura / Instituto do Patrimônio Histórico e Artístico Nacional /Departamento de Museus e Centros Culturais, Belo Horizonte: Secretaria de Estado da
Cultura / Superintendência de Museus. p. 33-79.

Carvalho, I. S. (2010). Curadoria paleontológica. In: Carvalho, I. S. (Ed.). (2010). Paleontologia: conceitos e métodos, v. 1, 3 ed. Rio de Janeiro: Interciência. p. 373-383.

Chagas, M. S. (2003). O Pai de Macunaíma e o patrimônio espiritual. In: Abreu, R., Chagas, M. S. (Org.). (2003). Memória e patrimônio: ensaios contemporâneos. Rio de Janeiro: DP\&A. p. 95-108.

Cruz, L. A. (2019). O papel da curadoria no gerenciamento de coleções museológicas de paleontologia no Brasil. Dissertação (Mestrado em Preservação e Gestão do Patrimônio Cultural das Ciências e da Saúde), Fundação Oswaldo Cruz. Casa de Oswaldo Cruz, $133 \mathrm{p}$

Ferrez, H. D. (1994). Documentação museológica: teoria para uma boa prática. IPHAN. Rio de Janeiro: IPHAN, Estudos Museológicos. p. 65-74 (Cadernos de Ensaios, 2). URL: http://pt.scribd.com/ doc/38689114/Documentacao-Museologica-Helena-Dodd-Ferrez. Acesso 25.08.2021.

Figueiredo, F. A. S. (2014). Salvaguarda do patrimônio fossilifero no espaço museu: um estudo de caso sobre os processos de formação e curadoria das coleções paleontológicas pertencentes ao Museu da Geodiversidade. Dissertação de Mestrado em Museologia e Patrimônio, Universidade Federal do Estado do Rio de Janeiro (Unirio), Museu de Astronomia e Ciências Afins (MAST). 249p.

Gonçalves, J. R. S. (2007). Antropologia dos objetos: coleções, museus e patrimônios. Museu, memória e cidadania. Rio de Janeiro, Ministério da Cultura, Instituto do Patrimônio Histórico e Artístico Nacional. Departamento de Museus e Centros Culturais. Ed. Garamond. 256p.

Kunzler, J., Machado, D. M. C., Novaes, M. G. L., Ponciano, L. C. M. O. (2014). Coleções Paleontológicas como Proteção do Patrimônio Científico Brasileiro. In: III Seminário Internacional Cultural Material e Patrimônio da Ciência e Tecnologia, Rio de Janeiro. Anais do III Seminário Internacional. v. 01.

Lemos, C. A. C. (1981). O que é patrimônio histórico. São Paulo: Ed. Brasiliense. 115p. (Col. Primeiros Passos, 51).

Lima, J. T. M., \& Carvalho, I. S. (2020). Políticas de curadoria e preservação em acervos de ciência e tecnologia: uma análise comparativa da gestão de coleções de geologia e paleontologia no Brasil. Boletim do Centro Português de Geo-História e Pré-História, 2(1), 17-27.

Museu da Geodiversidade (MGeo). Rio de Janeiro, Universidade Federal do Rio de Janeiro (UFRJ). URL: http://www.museu.igeo.ufrj.br/author/mgeo. Acesso 26.08 .2021

Pomian, K. (1984). Colecção. Enciclopédia Einaudi. Porto: Imprensa Nacional / Casa da Moeda. p. 51-86.

Semedo, A. (2005). Que museus universitários de ciências físicas e tecnológicas. Colecções de ciências físicase tecnológicas em museus universitários: homenagem a Fernando Bragança Gil. Porto, Universidade do Porto. Faculdade de Letras. Departamento de Ciências e Técnicas do Património. Secção de Museologia, 265-281. URL: https://repositorio-aberto.up.pt/bitstream/10216/21115/2/7656000087667. pdf. Acesso 24.08.2021. 